\section{Australian Journal of Crop Science}

\title{
Synthetic images to map daily evapotranspiration in field scale using SEBAL model and ESTARFM algorithm
}

\author{
Bruno Bonemberger da Silva ${ }^{{ }^{*}}$, Erivelto Mercante ${ }^{2}$, Douglas Kusminski ${ }^{2}$, Carlos Eduardo Vizzotto Cattani ${ }^{2}$, \\ Isaque de Souza Mendes ${ }^{2}$, Ivã Luis Caon ${ }^{2}$, Diandra Ganascini ${ }^{2}$, Maritane Prior ${ }^{2}$ \\ ${ }^{1}$ Maringá State University, Campus Arenito, Cidade Gaúcha, PR, Brazil \\ ${ }^{2}$ Western Paraná State University, Cascavel, PR, Brazil
}

*Corresponding author: brnosilva_b@hotmail.com

\section{Abstract}

Many applications in water resource management require evapotranspiration (ET) information at the daily and field-level scales; however, no satellite system currently operating is able to capture all the resources of ET dynamics in an agricultural field. Thus, the objective of this study was to apply the SEBAL (Surface Energy Balance Algorithm for Land) and ESTARFM (Enhanced Adaptive Reflectance Fusion Model) methodology to estimate the daily ET in an agricultural area in the municipality of Cascavel, Paraná. We applied the ESTARFM algorithm to MODIS and Landsat 8 images to produce 8 synthetic images. The performance of the algorithm was evaluated by comparing predicted surface reflectance values obtained to real Landsat 8 images. SEBAL was applied to obtain daily evapotranspiration values $\left(\mathrm{ET}_{24}\right)$ for 3 different targets (maize, soybean and stubble crop). The observed results showed that the predictions of ET using ESTARFM had a general determination coefficient of 0.80 in all analyzed images and ranged from $0.4<R^{2}<0.81$ when compared with real data from the Landsat 8 images, with soybean crop yielding the worst results. Low error values were found between the synthetic time series data of ET and the real data, with mean less than $1 \mathrm{~mm} \mathrm{day}^{-1}$, meaning high reliability of synthetic data. ESTARFM tended to overestimate the ET values when compared with the real data, with the performance strongly affected by a change in the soil cover between the analyzed dates. Input data with the same soil cover is recommended for more accurate results.

Keywords: Data fusion; ESTARFM; Landsat 8; MODIS; SEBAL.

\section{Introduction}

The increase in food production is extremely important in view of the population growth trend; thus, increasing agricultural production is fundamental for food and energy security. Therefore, understanding the factors that affect crop yields, such as evapotranspiration (ET), will be important to confronting future agricultural fluctuations caused by global climate change, water demand, or soil limitations (Holzman et al., 2018).

The use of ET in irrigation is more common; however, it is also increasingly used to determine the irregular use of water, parameterize hydrological processes, estimate biomass and crop production, plan and operate water resources, monitor climate and climate change, participate in forecasting models, and assist in the management and allocation of water in regions with water stress and between states and nations (Allen et al., 2011; Anderson et al., 2012; Paredes et al., 2015).

ET is typically modeled using meteorological data and algorithms describing surface energy and vegetation characteristics (Allen et al., 2011). In this context, ET estimates obtained through remote sensing based on thermal infrared (TIR) data have become increasingly common owing to the variety of available satellites
(Cammalleri et al., 2014; Campos et al., 2017; Silva et al., 2018).

Among the algorithms used, the SEBAL (Surface Energy Balance Algorithm for Land) proposed by Bastiaanssen et al. (1998) has considerable importance as it can be applied to spectral data of any remote satellite sensor that make radiance measurements in the visible, near infrared, and thermal infrared regions of the spectrum.

Despite the great technological advances in the areas of remote sensing and environmental modeling, there are still some deficiencies in the current dataset (e.g., data gaps, deviations, inaccurate calibration, low spatial or temporal resolution), generating limitations in the applicability of ET to high space and time resolution monitoring (Anapalli et al., 2018; Cammalleri et al., 2014).

Because no currently operating TIR satellite system is capable of capturing all the resources of ET dynamics in an agricultural field, the data fusion approach using the Enhanced Adaptive Reflectance Fusion Model (ESTARFM) has been identified as a valuable means to combining ET maps using the SEBAL algorithm applied to high spatial resolution Land Remote Sensing Satellite (Landsat 8 OLI/TIRS) data and high temporal frequency Moderate 
Resolution Imaging Spectroradiometer (MODIS) data. Therefore, synthetic images derived from the temporal space fusion have great value in studies related to agriculture, climate, and the environment (Cammalleri et al., 2014; Mukherjee et al. 2014).

With this in mind, the objective of this study was to apply the SEBAL model and ESTARFM methodology to estimate daily ET on an agricultural property. The main tasks were: (1) Estimate daily ET using synthetic images from Landsat 8 OLI/TIRS and MODIS images and evaluate ESTARFM performance, comparing ET data with real Landsat 8 OLI/TIRS images; (2) analyze ET temporally and spatially from synthetic images on the farm and evaluate its applicability.

\section{Results and discussion}

\section{ESTARFM performance}

To evaluate the performance of ET estimated using synthetic images $\left(E T_{s}\right)$ from the ESTARFM algorithm, these values were compared with those of ET estimated with real data from Landsat 8 images $\left(\mathrm{ET}_{\mathrm{L} 8}\right)$. Three statistical indexes (rootmean-square error, RMSE; mean absolute difference, MAD, and relative error, $\mathrm{RE}$ ) were used to evaluate the ET results. The $\mathrm{ET}_{\mathrm{S}}$ and $\mathrm{ET}_{\mathrm{L8}}$ estimated with a spatial resolution of $30 \mathrm{~m}$ were compared for different targets (soybean, maize, and stubble crop), which were observed on the property evaluated between October 2014 and October 2015. The RMSE values for soybean, maize, and stubble crop were 0.42 $\mathrm{mm} \mathrm{day}{ }^{-1}, 0.39 \mathrm{~mm} \mathrm{day}^{-1}$, and $2.46 \mathrm{~mm} \mathrm{day}^{-1}$, the MAD values were $0.22 \mathrm{~mm}$ day $^{-1}, 0.16 \mathrm{~mm} \mathrm{day}^{-1}, 0.10 \mathrm{~mm} \mathrm{day}^{-1}$, and the $\mathrm{RE}$ values were $13 \%, 8 \%$, and $48 \%$, respectively (Table 1). The values of the errors were lower than those found by Cammalleri et al. (2014), except for corn, with their RMSE values ranging from $1.11 \mathrm{~mm} \mathrm{day}^{-1}$ to $1.81 \mathrm{~mm} \mathrm{day}^{-1}$ and $\mathrm{RE}$ values ranging from $20.8 \%$ to $26.6 \%$ for irrigated areas.

With regression analysis, the dispersion points were observed to be generally concentrated near the line $x=y$ (Figure 1). For the coefficient of determination $\left(R^{2}\right)$, comparing the estimates between ETS and ETR yielded values of 0.81 for soybean, 0.79 for maize, and 0.40 for stubble crop, and when analyzed for all crops, the general coefficient was 0.80 , showing good concordance between the data analyzed, except for the results found for corn. Bai et al. (2017), using ESTARFM for ET determination in agricultural crops, obtained a similar result for soybean with an $R^{2}$ of 0.79 and a superior result for maize with an $R^{2}$ coefficient of 0.85 .

The worst results were observed to be strongly influenced by the dates of the images used as input data for ESTARFM, with a change in the soil cover characterizing the difference between the two dates of corn and those of soybean. This highly dynamic use of soil impairs the performance of the algorithm due to the different spectral responses of the targets (Yin et al., 2018; Zhu et al., 2017). In addition, accuracy is reduced when the field size is smaller than a MODIS pixel; in some pixels, there was spectral mixing between the agricultural area and adjacent areas.

\section{ET images}

The daily ET values estimated with ESTARFM (ETs) in the eight images analyzed ranged from 0 to $10.2 \mathrm{~mm} \mathrm{day}^{-1}$ (Figure 2), with a mean of $6 \mathrm{~mm} \mathrm{day}^{-1}$. The ET distribution reflected the developed stage of the agricultural crops in the study area between Oct 2014 and Oct 2015. It is observed that on Jan 22, 2015 and Oct 05, 2015, the lowest values of ET were concentrated, because at the time of these images, the soybean crop was found in senescence, and in the second image, the soil was with stubble crop. Meanwhile, the largest data were recorded in the image of Apr 12, 2015 in which the maize was at its vegetative peak.

It was observed in the comparative time series between ETL8, ETS, and ETO (Figure 3) that the mean values ranged from 4-8 $\mathrm{mm} \mathrm{day}^{-1}$, and the results obtained by the synthetic images exhibited good precision when compared with the real images from Landsat 8 , with a difference between the means of always less than $1 \mathrm{~mm} \mathrm{day}^{-1}$. Cammalleri et al. (2013), using data fusion in Landsat and MODIS images obtained errors of the order of $0.6 \mathrm{~mm} \mathrm{day}^{-1}$. In general, ESTARFM tended to overestimate the data except for Feb 07, 2015. A similar pattern was found by Ma et al. (2018), evaluating ESTARFM in agricultural areas in northwest China. According to Semmens et al. (2016), there may be several explanations for this overestimation, such as spectral mixing and times chosen for data entry. Wang et al. (2018), testing the fusion of data to produce ET maps using data from area photos to ASTER images (spatial resolution varying from $3 \mathrm{~m}$ to $90 \mathrm{~m}$ ), observed that the obtained ET became slightly overestimated as the sensor resolution decreased.

\section{Mean of ET during soybean and maize cycles}

To analyze the potential of the synthetic images in the monitoring of ET at high temporal resolution, similar to that of the MODIS and the spatial sensor of Landsat, synthetic images with ET data were analyzed during the crop cycle of soybean and maize (Figure 4). The dates chosen corresponded to the stages of vegetative development considered critical for water stress, reflecting in a decrease in ET and loss of production.

It was observed that during the analyzed period, mainly in October 2014, the total precipitation recorded by the ECMWF data was well below that expected for the municipality of Cascavel (Caviglione et al., 2000), which may have been reflected in the lower than expected ET values for soybeans.

The critical time related to soybean water stress corresponds to the flowering stage, stages $R 1$ to $R 6$, where the expected ET is between $6-8 \mathrm{~mm}$ per day (Farias et al., 2007). The reproductive stages began 54 days after sowing according to Meschede et al. (2004), corresponding to approximately half of the cycle, represented by the crop image of Dec. 05, 2014, which presented ET lower than expected, a value of $5.6 \mathrm{~mm} \mathrm{day}^{-1}$.

The ET expected for maize in its time most sensitive to water stress is between 8-9 mm day ${ }^{-1}$ in its R1 stage (Albuquerque; Resende, 2002), corresponding to the image of Apr. 12, 2015 , which presented the highest of the averages among the analyzed images, with a value of $8 \mathrm{~mm} \mathrm{day}^{-1}$. 
Table 1. Accuracy Analysis of the ESTARFM algorithm for daily Evapotranspiration (ET).

\begin{tabular}{lllll}
\hline Crop & RMSE $\left(\mathrm{mm} \mathrm{day}^{-1}\right)$ & $\mathrm{MAD}\left(\mathrm{mm} \mathrm{day}^{-1}\right)$ & $\mathrm{RE}(\%)$ & $\mathrm{R}^{2}$ \\
\hline Soybean & 0.42 & 0.22 & 13 & 0.81 \\
Maize & 0.39 & 0.16 & 8 & 0.79 \\
Stubble crop & 2.46 & 0.1 & 48 & 0.4 \\
General & 1.81 & 1.21 & 30 & 0.79 \\
\hline
\end{tabular}
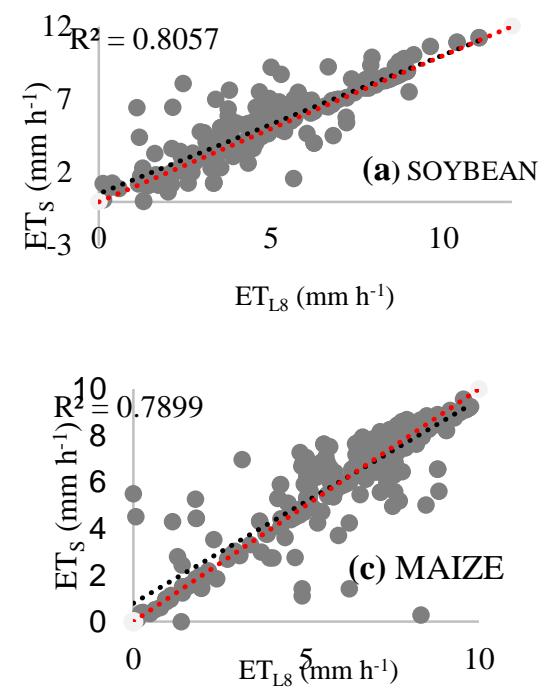
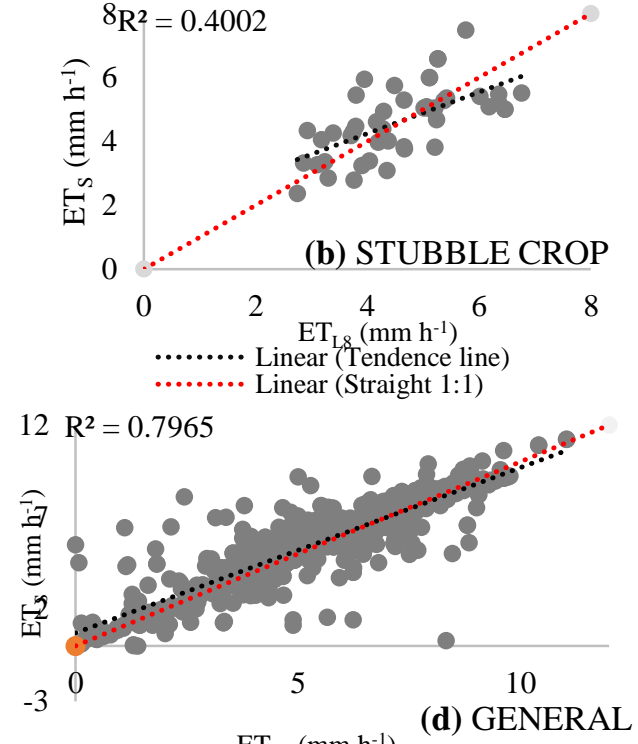

Fig 1. Comparison between ETs (calculated using synthetic ESTARFM images) and ETL8 (calculated using actual Landsat 8 image data): (a) Soybean, (b) Stubble crop, (c) Maize, (d) General.
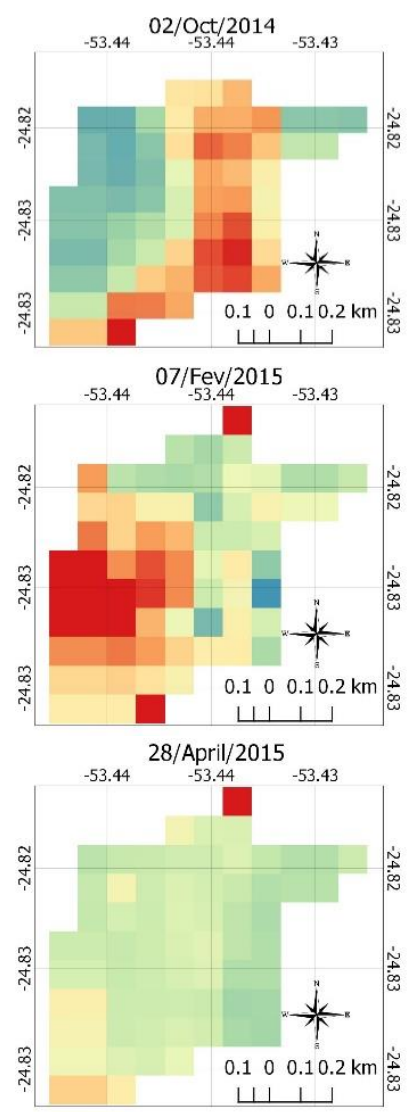
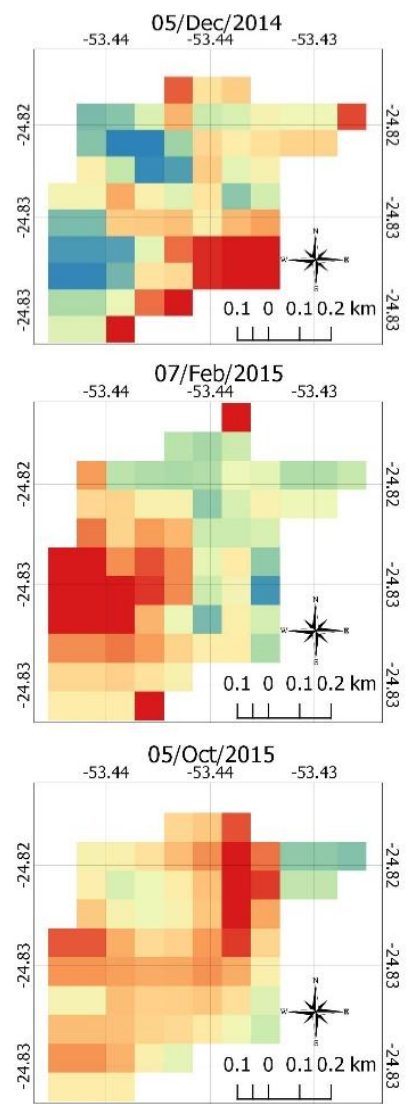
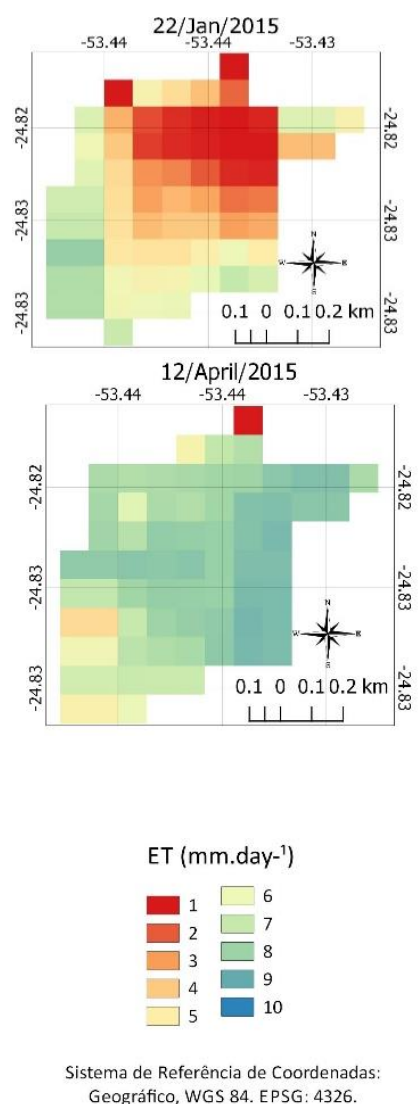

Fig 2. Spatial distribution of Evapotranspiration (ET) with synthetic images for images between October 2014 and October 2015. The colors in the image correspond to the ET values $\left(\mathrm{mm}^{\left.- \text {day }^{-1}\right)}\right.$ obtained from the synthetic images by the SEBAL algorithm, ranging from red $\left(1 \mathrm{~mm} \cdot \mathrm{day}^{-1}\right)$ to blue $\left(10 \mathrm{~mm} \cdot \mathrm{day}^{-1}\right)$. 


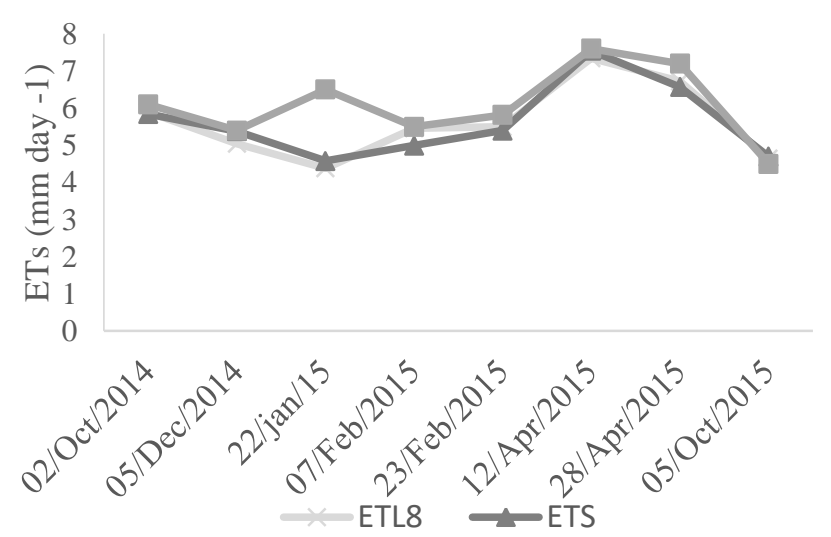

Fig 3. Time Series of ETL8, ETS and ETO for images analyzed between October 2014 and October 2015.
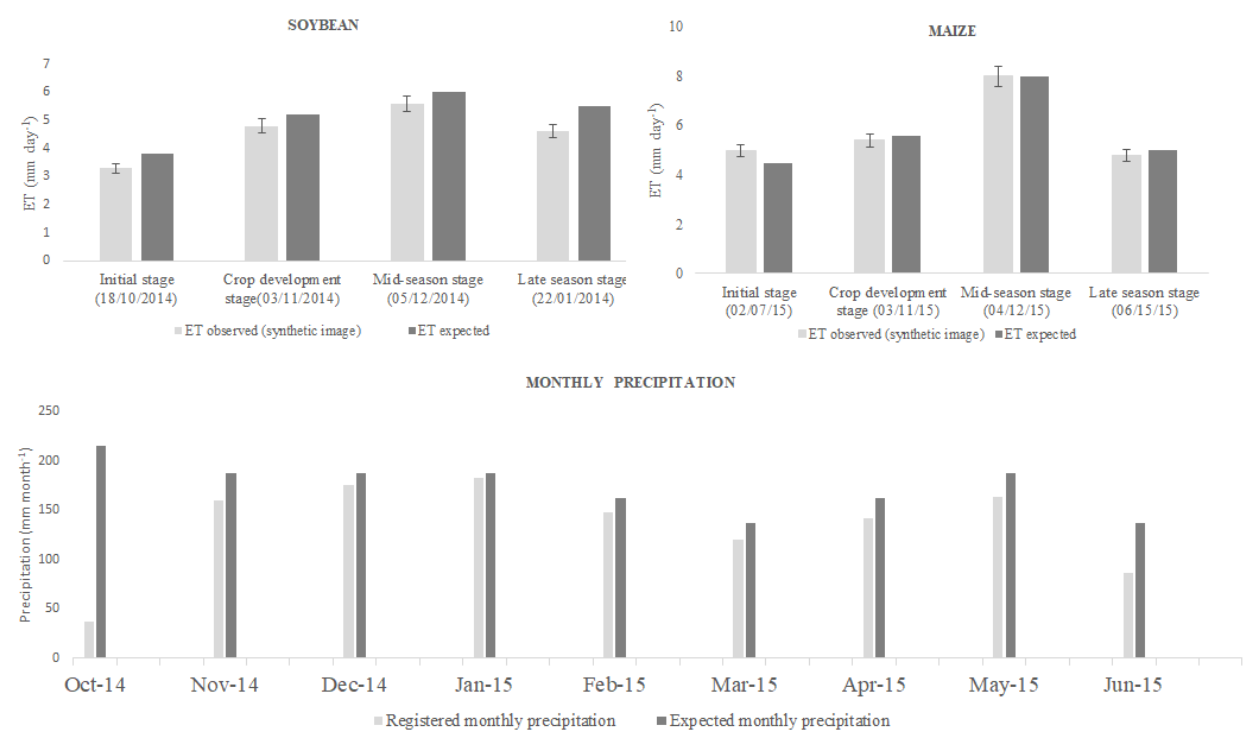

Fig 4. ET means obtained for the synthetic images and the ET value expected for each stage of development analyzed from the soybean (a) and maize (b) and monthly total precipitate in the period of analyzed images (c).
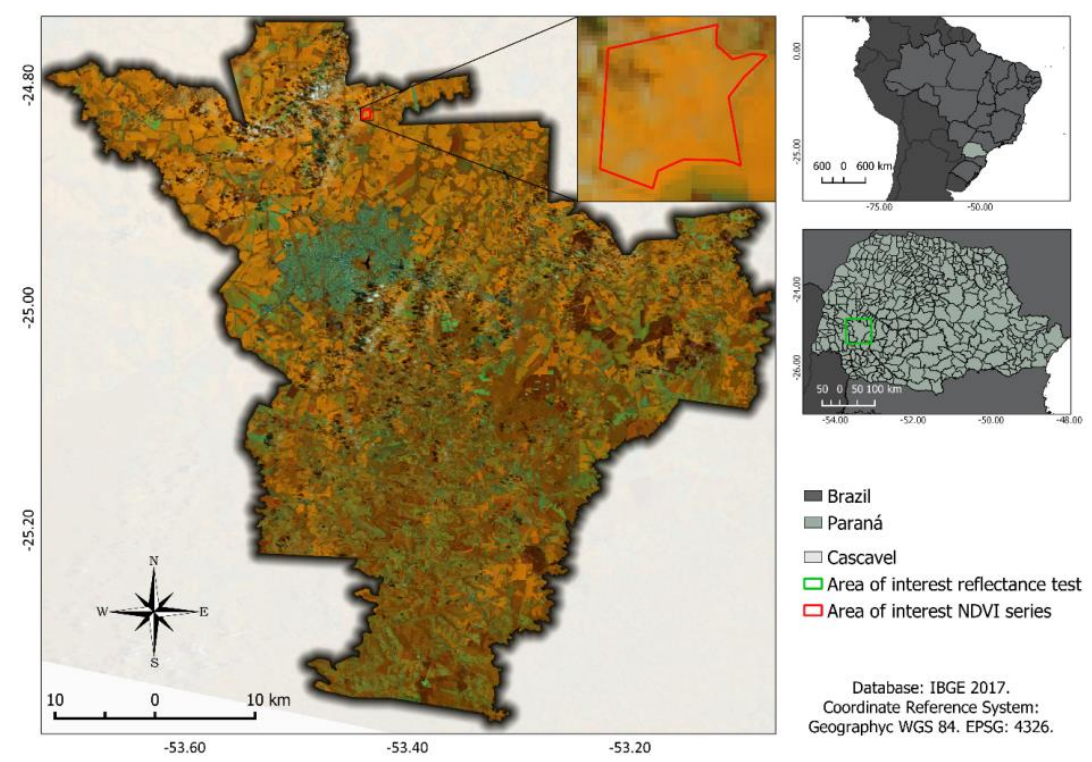

Fig 5. Location of the study area. The Landsat-8 image (false-color RGB image using bands 5, 6 and 4) was acquired on December 5 , 2014. It is possible to observe the predominance of agricultural targets, native vegetation and reforestation. 
The largest volume of rainfall was recorded in the period, which may have contributed to the observed result.

\section{Materials and methods}

\section{Study area}

The study area is an agricultural property in the municipality of Cascavel, Paraná (Figure 5), with latitude 240 49' 35" S and longitude 53 26' $12^{\prime \prime} \mathrm{W}$ with the predominant soil Dystroferric Red Latosol (EMBRAPA, 2011). The climate of the studied region is characterized as temperate mesothermic and superhumid, climate type Cfa (Aparecido et al., 2016), with moderate temperatures, well-distributed rains, and hot summers. In the winter months, the average temperature is below $16^{\circ} \mathrm{C}$, and in the summer months, the maximum temperatures exceed $30{ }^{\circ} \mathrm{C}$, with an average annual temperature of $21^{\circ} \mathrm{C}$.

The first crop that occupied the area during the period of interest was the soybean, sown on the dates between October 6 and 7, 2014, and a harvest was held on February 3-6 2015. A successive crop was maize, sowed between February 10 and 12, 2015 with a harvest between June 5-9, 2015. After that date until the beginning of October, the soil was covered with maize stubble.

\section{Satellite Data}

Eight images were acquired between October 2014 and October 2015 from the Landsat 8 OLI/TIRS satellite orbit/point 223/77 (with cloud percentage less than 10\%), and the MOD09GQ and MYD09GQ products of the MODIS sensor Terra and Aqua platforms from the h12v11 scene. All MODIS images were reprojected to Universal Transverse Mercator (UTM) projection using the MODIS Reprojection Tool (Kalvelage; Willems 2005), re-sampled for a spatial resolution of $30 \mathrm{~m}$, using the nearest neighbor approach and cropped to the same extent as Landsat images. Images from both satellites were provided free of charge by the USGS (https://earthexplorer.usgs.gov/).

\section{SEBAL algorithm}

The SEBAL model was developed using existing modules and created in GRASS Open Source GIS (Alexandridis et al., 2009). SEBAL uses spectral images from the visible, near infrared, and thermal infrared regions to calculate the pixelto-pixel energy balance. In SEBAL, $R_{n}$ is calculated from the satellite broadband reflectance and the surface temperature, while $G$ is estimated from $R_{n}$, surface temperature, and vegetation indices. The sensible heat flux $H$ is proportional to the ratio of the surface air temperature difference (dT) to the aerodynamic resistance (rah). SEBAL uses the partitioning of $\lambda E T$ described in Bastiaanssen et al. (1998), in which the evaporative fraction $(\Lambda)$ is calculated according to Eq. (1).

$$
\Lambda=\frac{\lambda E T}{\lambda E T+H}=\frac{\lambda E T}{R_{n}-\mathrm{G}}
$$

Meteorological studies indicate that the instantaneous evaporative fraction is almost constant in time (Ayenew, 2003). Thus, at daily time scales, $\mathrm{ET}_{24}\left(\mathrm{~mm} \mathrm{~d}^{-1}\right)$ can be calculated as shown in Eq. (2)
$E T_{24}=\frac{86400}{\lambda} \Lambda R_{n 24}$

where $R_{n 24}\left(W m^{-2}\right)$ is the average net radiation over $24 \mathrm{~h}$, and $\lambda\left(\mathrm{J} \mathrm{kg}^{-1}\right)$ is the latent heat of vaporization.

In addition to the satellite images, the SEBAL model requires ETO values, and these meteorological data were obtained from the European Center for Medium-Range Weather Forecasts (ECMWF) provided on its website, with a resolution of $0.125^{\circ} \times 0.125^{\circ}$ (http://apps.ecmwf.int/datasets/data/interim-fulldaily/levtype=sfc).

\section{ESTARFM algorithm}

The ESTARFM algorithm is intended to use correlation to merge different data sources, thereby minimizing system distortions. For convenience, low spatial resolution images are called "coarse resolution" and high-resolution images are referred to as "fine resolution". In the first step of the processing, the algorithm requires two pairs of fine resolution images and coarse resolution as input-the first pair is called $t_{1}$ and the second pair is $t_{2}$, both captured on the same date. The estimated date of production is called $t_{p}$, which falls between dates $t_{1}$ and $t_{2}$ and requires a coarseresolution image, in this case, a MODIS image. Thus, ESTARFM is able to produce a synthetic image at prediction date $t_{p}$ with the same spatial resolution as that of the fine resolution images (Zhu et al., 2010).

The use of ESTARFM contains four main steps: (1) two fineresolution images are used to search for pixels similar to the central pixel in a moving window, (2) the spectral and spatial distance between each pixel similar to the pixel to be predicted are used to calculate the weights (W) of each similar pixel, (3) a linear regression of the coarse-resolution values is used in the two observed pairs $\left(t_{1}\right.$ and $\left.t_{2}\right)$ to compare with the fine-resolution values; this permits the determination of the conversion coefficient $v_{i}$, which is used to convert the change found in the coarse-resolution images to that of the fine resolution images, and finally (4) the fineresolution image obtained from the coarse-resolution image at the forecast date is given by Eq. (3)

$\mathrm{F}\left(\mathrm{x}, \mathrm{y}, \mathrm{t}_{\mathrm{p}}\right)=\mathrm{F}\left(\mathrm{x}, \mathrm{y}, \mathrm{t}_{0}\right)+\sum_{\mathrm{i}=1}^{\mathrm{N}} \mathrm{w}_{\mathrm{i}} \times \mathrm{v}_{1} \times\left(\mathrm{C}\left(\mathrm{x}_{\mathrm{i}}, \mathrm{y}_{\mathrm{i}}, \mathrm{t}_{\mathrm{p}}\right)-\mathrm{C}\left(\mathrm{x}_{\mathrm{i}}, \mathrm{y}_{\mathrm{i}}, \mathrm{t}_{0}\right)\right)$

Where, $\mathrm{F}$ and $\mathrm{C}$ are the fine-resolution and coarse-resolution images, respectively, $(x, y)$ is the location of the predicted pixel value, $x_{i}$ and $y_{i}$ are the locations of the $i$-th similar pixel, and $t_{0}$ is the date of the first pair of images, $t_{1}$ or $t_{2}$. $N$ is the total number of similar pixels, including the central pixel of the prediction inside the moving window (Zhu et al., 2010).

The methodology presented by Gao et al. (2006) uses a moving window method to obtain more information regarding neighboring pixels. The moving window is used to search for similar pixels within this window, and such information is integrated into the calculation of the fineresolution reflectance, as described in Eq. (1), where $W$ is the size of the moving window, and the central pixel of the fine-resolution reflectance $\left(x_{w / 2}, y_{w / 2}\right)$ at date $t_{p}$ can be calculated by Eq. (4).

$\mathrm{F}\left(\mathrm{x}_{\frac{\mathrm{w}}{2}}, \mathrm{y}_{\frac{\mathrm{w}}{2}}, \mathrm{t}_{\mathrm{p}}, \mathrm{B}\right)=\mathrm{F}\left(\mathrm{x}_{\frac{\mathrm{w}}{2}}, \mathrm{y}_{\frac{\mathrm{w}}{2}}, \mathrm{t}_{0}, \mathrm{~B}\right)+\sum_{\mathrm{i}=1}^{\mathrm{N}} \mathrm{w}_{\mathrm{i}} \times \mathrm{v}_{1} \times\left(\mathrm{C}\left(\mathrm{x}_{\mathrm{i}}, \mathrm{y}_{\mathrm{i}}, \mathrm{t}_{\mathrm{p}}, \mathrm{B}\right)-\mathrm{C}\left(\mathrm{x}_{\mathrm{i}}, \mathrm{y}_{\mathrm{i}}, \mathrm{t}_{0}, \mathrm{~B}\right)\right)$ Where, $\mathrm{N}$ is the number of similar pixels, including the central pixel of the "prediction", $\left(x_{i}, y_{i}\right)$ is the location of the $\mathrm{i}$-th similar pixel, and $\mathrm{w}_{\mathrm{i}}$ is the weight of the $\mathrm{i}$-th similar pixel. 
The similar pixels are those neighboring pixels that have the same type of coverage as the central pixel.

\section{Conclusions}

ESTARFM can be applied to estimate ET with high spatial and temporal resolution through the fusion of Landsat 8 and MODIS images, estimating water consumption by agricultural crops. The best results were found for soybean with an $R^{2}$ of 0.81 , while the worst results involved stubble crop with an $R^{2}$ of 0.41 . The algorithm tended to overestimate the values when compared with real Landsat 8 images.

The synthetic images allowed the systematic monitoring of the crop, facilitating the determination of dates sensitive to the water stress of the plant, which would not be possible with sensors alone.

The choice of dates for the input data plays a large role in performance, considering that the worst results were obtained when the data used corresponded to a change in the soil cover between the dates analyzed for the study area.

\section{Acknowledments}

To Coordenação de Aperfeiçoamento de Nível Superior (Capes), and Conselho Nacional de Desenvolvimento Científico e Tecnológico (CNPq), and Foundation Itaipu Technological Park (FPTI).

\section{References}

Albuquerque P EP, Resende M (2002) Cultivo do milho: manejo de irrigação. Embrapa Milho e Sorgo.

Alexandridis TK, Cherif I, Chemin Y, Silleos GN, Stavrinos E, Zalidis G (2009). Integrated methodology for estimating water use in mediterranean agricultural areas. Remote Sens-Basel, 1(3): 445465.

Allen RG, Pereira LS, Howell TA, Jensen ME (2011) Evapotranspiration information reporting: I . Factors governing measurement accuracy. Agr Water Manage. 98(6): 899-920 .

Anapalli SS, Verde TR, Reddy KN, Gowda PH, Sui R, Fisher DK, Moorhead JE, Marek GW (2018) Application of an energy balance method for estimating evapotranspiration in cropping systems. Agr Water Manage, 204: 107-117.

Anderson MC, Allen RG, Morse A, Kustas WP (2012) Use of Landsat thermal imagery in monitoring evapotranspiration and managing water resources. Remote Sens Environ. 122: 50-65.

Aparecido LEO, Rolim GS, Richetti J, De Souza PS, Johann JA (2016) Köppen, Thornthwaite and Camargo climate classifications for climatic zoning in the State of Paraná, Brazil . Cienc Agrotec. 40(4): 405-417.

Ayenew T, (2003) Evapotranspiration estimation using thematic mapper spectral satellite data in the Ethiopian rift and adjacent highlands. J Hydrol. 279: 83-93.

Bai L, Cai J, Liu Y, Chen E, Zhang B, Huang L (2017) Responses of field evapotranspiration to the changes of crowwpping pattern and groundwater depth in large irrigation district of Yellow River basin. Agr Water Manage. 188: 1-11.

Bastiaanssen, WGM, Manenti MA, Feddes RA, Holtslag AA (1998) Remote sensing surface energy balance algorithm for land ( SEBAL ). J Hydrology. 212: 198-212.

Cammalleri C, Anderson MC, Gao F, Hain CR, Kustas WP (2013) A data fusion approach for mapping daily evapotranspiration at field scale. Water Resour Res. 49(8): 4672-4686.

Cammalleri C; Anderson MC; Gao F; Hain CR; Kustas WP (2014) Mapping daily evapotranspiration at field scales over rainfed and irrigated agricultural areas using remote sensing data fusion. Agr Forest Meteorol. 186: 1-11.

Campos I, Neale CM, Suyker MU, Suyker AE, Arkebauer TJ, Gonçalves IZ (2017) Reflectance-based crop coefficients REDUX: For operational evapotranspiration estimates in the age of high producing hybrid varieties. Agr Water Manage. 187: 140-153.

Caviglione JH, Kiihl LRB, Caramori PH, Oliveira D (2000) Cartas climáticas do Paraná. IAPAR, Londrina, CD-Rom.

EMBRAPA (2011). O novo mapa de solos do Brasil: legenda atualizada Rio de janeiro Dados eletrônicos - Embrapa Solos.

Farias JRB, Nepomuceno AL, Neumaier N (2007) Ecofisiologia da soja. Embrapa Soja.

Gao F, Masek J, Schwaller M, Hall F (2006) On the Blending of the Landsat and MODIS Surface Reflectance : Predicting Daily Landsat Surface Reflectance. leee T Geosci Remote, 44 (8): 2207-2218.

Holzman ME, Carmona F, Rivas R, Niclòs (2018) Early assessment of crop yield from remotely sensed water stress and solar radiation data. Isprs J Photogramm. 145: 297-308.

Kalvelage T, Willems J (2005) Supporting users through integrated retrieval, processing, and distribution systems at the land processes distributed active archive center. Acta Astronaut. 56 (7): 681-687.

Ma Y, Liu S, Song L, Xu Z, Liu Y, Xu T, Zhu Z (2018) Estimation of daily evapotranspiration and irrigation water efficiency at a Landsat-like scale for an arid irrigation area using multi-source remote sensing data. Remote Sens Environ. 216: 715-734.

Meschede DK, Oliveira Jr RS, Constantin J, Scapim CA (2004) Period Before Weed Interference in Soybean: a Case-Study Under Low Crop Density and Twofold Checks. Planta Daninha. 22 (2): 239246

Mukherjee S, Joshi PK, Garg RD (2014) A comparison of different regression models for downscaling Landsat and MODIS land surface temperature images over heterogeneous landscape. Adv Space Res. 54 (4): 655-669.

Paredes P, Wei Z, Liu Y, Xin Y, Zhang B, Pereira LS (2015) Performance assessment of the FAO aquaCrop model for soil water, soil evaporation, biomass and yield of soybeans in north china plain. Agr Water Manage. 152: 57-71.

Silva BB, Mercante E, Vilas Boas MA, Wroblack SC, Oldoni LV (2018) Satellite-based ET estimation using Landsat 8 images and SEBAL model. Rev Cienc Agron. 49(2): 221-227.

Semmens KA, Anderson MC, Kustas WP, Gao F, Alfieri JG, Mckee L, Pruger JH, Hain CR, Cammalleri C, Yang Y, Xia T, Sanchez L, Alsina MM, Vélez M (2016) Monitoring daily evapotranspiration over two California vineyards using Landsat8 in a multi-sensor data fusion approch. Remote Sens Environ. 185: 155-170.

Yin G, Li A, Jin H, Bian J (2018) Spatiotemporal fusion through the best linear unbiased estimator to generate fine spatial resolution NDVI time series. Int J Remote Sens. 39 (10): 3287-3305.

Wang T, Tang R, Li Z, Tang B, Wu H, Jiang Y, Liu M (2018) A comparison of two spatio-temporal data fusion schemes to increase the spatial resolution of mapping actual evapotranspiration. Paper presented at the IGARSS 2018 - 2018 IEEE International Geoscience and Remote Sensing Symposium, Valencia, Spain, 2-27 July 2018.

Zhu L, Radeloff VC, Ives AR (2017) Improving the mapping of crop types in the Midwestern U.S. by fusing Landsat and MODIS satellite data. Int J Appl Earth Obs. 58: 1-11.

Zhu X, Chen J, Gao F, Chen X, Masek JG (2010) An enhanced spatial and temporal adaptive reflectance fusion model for complex heterogeneous regions. Remote Sens Environ. 114: 2610-2623. 